\title{
Collaborative virtual gaming worlds in higher education
}

\author{
Nicola Whitton ${ }^{\mathrm{a} *}$ and Paul Hollins ${ }^{\mathrm{b}}$ \\ ${ }^{a}$ Education and Social Research Institute, Manchester Metropolitan University, Manchester, UK; \\ ${ }^{b}$ University of Bolton, Bolton, UK
}

(Received 1 April 2008; final version received 8 September 2008)

\begin{abstract}
There is growing interest in the use of virtual gaming worlds in education, supported by the increased use of multi-user virtual environments (MUVEs) and massively multiplayer online role-playing games (MMORPGs) for collaborative learning. However, this paper argues that collaborative gaming worlds have been in use much longer and are much wider in scope; it considers the range of collaborative gaming worlds that exist and discusses their potential for learning, with particular reference to higher education. The paper discusses virtual gaming worlds from a theoretical pedagogic perspective, exploring the educational benefits of gaming environments. Then practical considerations associated with the use of virtual gaming worlds in formal settings in higher education are considered. Finally, the paper considers development options that are open to educators, and discusses the potential of Alternate Reality Games (ARGs) for learning in higher education. In all, this paper hopes to provide a balanced overview of the range of virtual gaming worlds that exist, to examine some of the practical considerations associated with their use, and to consider their benefits and challenges in learning and teaching in the higher education context.
\end{abstract}

Keywords: virtual environments; game-based learning; constructivist learning environments

\section{Introduction}

The growing popularity of multi-user virtual environments (MUVEs), such as Second Life, and massive multi-player online role-playing games (MMPORG) like World of Warcraft has led to an increased interest in the use of such technologies for learning. However, different types of collaborative virtual gaming environments have actually been used for many years, and this paper aims to explore the wider context of these worlds and their potential for learning.

The focus here is unashamedly on the use of virtual gaming and multi-user environments with adults in the UK higher education sector. This is an area that the authors feel is often neglected in terms of research, or where assumptions are transferred from research with children or other groups; for example that games are a suitable educational tool because they allegedly lead to increased student motivation, which is not necessarily the case with adult learners, who may be time-poor and more strategic in their learning (Beasley and Crerar 2005). The authors acknowledge that research into the application of games and simulations for learning has a rich history, particularly in the military, corporate and health sectors, but

\footnotetext{
*Corresponding author. Email: n.whitton@mmu.ac.uk
} 
the focus of this paper is primarily on the use of games to teach higher-level cognitive skills within higher education.

This paper adopts an inclusive definition of an immersive virtual gaming world, so is not restricted to massively multi-user graphical online environments, but refers here to any computer-based environment that shares one or more game-like characteristics, including an environment that can be explored, a competitive element, a fantasy setting, goals, rules and outcomes, and interaction with others. The number of users in this broad definition can range from one to millions; as even single-user environments can still be collaborative, for example, by users working synchronously while using the environment. The fidelity of a virtual environment can vary from being entirely text-based, to using still images, twodimensional or three-dimensional graphics.

Using collaborative gaming environments to teach is not a new concept, with organisations such as the Society for the Advancement of Games and Simulations in Education and Training (SAGSET) dating back more than 35 years (van Ments 1995). However, the ubiquity of online collaborative communities and use of large-scale virtual worlds, coupled with the ever-growing power of computing technology, have increased the potential of computer-based collaborative learning in a way simply not possible before.

This paper will first consider the pedagogic benefits of collaborative game-based virtual worlds in relation to established constructivist theories of teaching and learning. It will then discuss some of the practical issues associated with using virtual worlds to teach in higher education. Next, options for the development and creation of virtual environments are presented, and the paper concludes by discussing some of the benefits and challenges of using virtual worlds.

\section{Pedagogy in virtual gaming worlds}

Collaborative virtual gaming environments can support a variety of pedagogic approaches and can be applied, for example, as both constructivist learning environments and as didactic instructional tools. This paper is concerned primarily with the constructivist perspective, which hypothesises that people learn by developing their own views about the world, by problem-solving and personal discovery. The design of student-centred online learning environments has been very much influenced by the constructivist perspective (e.g. Grabinger, Dunlap, and Duffield 1997; Land and Hannafin 2000). Honebein (1996) presents pedagogic goals of the design of constructivist learning environments in that they should: encourage students to take responsibility for their learning, including what and how they learn; provide multiple perspectives; create self-awareness of the learning process; make learning relevant and authentic; make learning a collaborative and interactive social experience; and use multiple modes of representation and rich media. Immersive virtual environments can provide the opportunity for learners to explore and navigate worlds using a range of media types, with authentic and purposeful contexts for practising learning that can be transferred to the real world, and they can present a context for problem-solving and interaction with others. The SimPLE project at The University of Strathclyde graduate law school (Hughes 2006) is a case that exemplifies this approach. It has created a 'trading zone' in virtual space, which provides students with bounded activities and 'open fields of practice' of self-directed activity in order to construct their own understandings.

Working collaboratively enables students to work to their strengths, develop critical thinking skills and creativity, validate their ideas, and appreciate a range of individual learning styles, skills, preferences and perspectives (McConnell 2000; Palloff and Pratt 2003). Participating in communities of practice provides a legitimate and ongoing way of learning 
from others as part of a group through apprenticeship and education in the context of the group norms, processes and identity (Lave and Wenger 1991). Online gaming communities provide a similar platform for collaboration and the ability to learn with others. For example, studies of leisure users of massively multi-user online role-playing games (MMORPGs) have found evidence of collaborative learning, development of communities of practice (Steinkuehler 2004) as well as the potential for learning a range of group skills, including the etiquette of meeting people, group management, co-operation and social interaction (Ducheneaut and Moore 2005).

The constructivist perspective also puts forward the idea that students learn better by experiencing for themselves and discovering their own meanings from their experiences. Gee (2003) argues that computer games reflect the experiential learning cycle (Kolb 1984) in that students must examine the virtual environment, reflect on the situation to form a hypothesis, further investigate the virtual world and see what effect their action has. While it is true that this cycle maps onto learning within the game world, it does not necessarily provide students with scope for meta-cognitive processes and reflection outside of the virtual world. Prensky (2001) argues that if games were used for learning, then "learning would happen almost without the learners realizing it, in pursuit of beating the game" (26). In the context of higher education, without the opportunity to support learners to understand the process, context and transferability of learning, the value of learning undertaken in this way is questionable. In relation to reflection, Prensky (2001) argues that reflection does occur within games, only at a greater speed, or "twitch speed" as he defines it, although this assertion is controversial. It is important to recognise that learning in virtual environments may be part of a larger process and other activities - including formal and informal 'affinity groups' or communities, and reflective practice - often surround their use.

Although many first year undergraduates may have more in common with school-based learners, there is a growing representation of mature learners in higher education. These individuals typically have more work and personal responsibilities, caring commitments and greater life experience. Adult learning theory (Knowles 1998) argues that adult learning (or 'androgogy') is different from children's learning and that the key characteristics of adult learners are that they need to know why they need to know something before they are willing to invest time and energy in learning it, they have a deep psychological need to be self-directing and to take responsibility for their learning, become ready to learn something when they need to know it to be able to use it in real-life, and are task-oriented in their learning.

Adult learning theory highlights the fact that motivation to learn is paramount and that learning activities must be purposeful for students to engage. This brings into question the acceptability of learning in virtual worlds with adult learners, who may perceive these environments as frivolous and time-wasting. There are misconceptions associated with play that might affect the acceptability of game-based learning, for both adults in higher education and children in school-based learning contexts (Egenfeldt-Neilson 2005), in that it is perceived by many as only for young children, as not being a respectable thing to do, and as an activity that is easy (Rieber 1996) or that the learning is somehow inauthentic.

Although outside the scope of this paper, it is also recognised that immersive virtual worlds can be used in the behaviourist tradition as tools for skill development in higher education in the sciences or medical domains.

While collaborative virtual gaming environments have the potential to engage students and support authentic, experiential and collaborative learning, there are many practical 
issues associated with their use in higher education, which are discussed in the following section.

\section{Virtual gaming worlds in practice}

There are many practical considerations when using virtual gaming worlds in learning and teaching in higher education. Foremost, it is essential to have a clear educational purpose for their use, and not simply because they are thought to be motivational. While computer games may be motivating for some, this is often not the case for adult learners, who may be more strategic in what and how they learn and will look to learn things in the most appropriate way (Knowles 1998). However, while adult learners may not be interested in learning with a game for its own sake, there is evidence that they will be happy to use them if they are perceived as an effective way to learn in that context (Whitton 2007).

Matching the in-world outcomes with the intended learning outcomes from use is another key issue. If the use of the environment does not closely match the curriculum, then students may be learning something, but it may not be relevant to the course of study. Built in to many entertainment games is the goal of learning to play the game itself, mastering the interface and discovering advanced features, which may detract from the learning value of the game.

Other practicalities such as the amount of time available both to develop or modify the gaming world and to use in teaching, space, whether a course is online or face-to-face, and resources available (e.g. access to computers with correct specifications) will also influence how and when gaming worlds can be integrated into teaching and learning. An issue often arises in university settings with gaming worlds being seen as inappropriate or with communications ports being automatically locked so that software can not be accessed; threedimensional immersive worlds also often require higher specifications of graphics cards or processors than are typical in university machines. University regulations may also affect how these worlds can be integrated and assessed, and impact on whether the use of a virtual gaming world is a supplemental activity, single or multiple use, or fundamental to the whole structure and design of a course; they can also affect whether, and how, learning in gaming worlds is assessed. It is particularly important to separate achievement in the gaming environment with achievement in the assessment so as not to disadvantage students who might be performing less well for reasons that are nothing to do with their level of learning (e.g. students who have problems navigating in a three-dimensional environment). Welldesigned assessment can encourage the development and integration of reflective and collaborative activities, for example considering how progress through the game could have been different in different circumstances, or working with others to produce a reflective report.

While gaming environments may provide experiential learning spaces, they do not necessarily provide students with scope for reflection and application of their learned knowledge and skills to the real world. Activities such as debriefing and structured reflection are essential to ensure appropriate mastery of specified learning outcomes, and these activities can be structured outside the virtual world. As not all gaming environments are collaborative in nature, it is important to consider how communication with others can be built in to the learning package. Ways of doing this include face-to-face discussion interspersed with periods of individual game play, two individuals playing the same game at the same time and discussing strategies, either face-to-face or using an online messaging facility, or asynchronous message boards supporting game play and problem-solving. 
Whitton (2007) developed a set of practical criteria for the design of gaming worlds for learning and teaching in higher education, from a constructivist viewpoint, focusing on highlevel cognitive skills such as application, analysis and evaluation (Bloom 1956). Existing design guidelines in related areas were reviewed and synthesised and an evaluation of a number of popular Internet games with potential for learning was carried out to examine their design characteristics. These two pieces of work were drawn together to produce a set of six criteria for the effective pedagogic design of educational games for students in higher education.

(1) The environment should support active learning by encouraging exploration, problem-solving, and enquiry, providing opportunities to test ideas and gain feedback, practice and consolidation. Opportunities for collaboration should also be provided and, as much as possible, game goals should align with learning outcomes. (This assumes, incorrectly, that collaborative learning is a prerequisite of 'all' learning; learning by rote or didactic approaches can be effective in complex skill and competency development in higher education. Examples exist in the medical and engineering disciplines.)

(2) The environment should engender engagement, with explicit and achievable goals, provision of a large world to be explored with a high level of interactivities, multiple pathways, and different ways in which success can be achieved. The world should stimulate the user's curiosity and provide an appropriate level of challenge and control of the environment. This, however, assumes a level of competence of the course designer to develop 'engaging' immersive content and activities in the gaming medium, therefore a minimum requirement would be significant personal development planning for educators to support development of their gaming literacy or development competence.

(3) The gaming world should be appropriate for the learning context, in that it fits with, or is at least relevant to, curriculum and assessment, is suitable for the subject area, matches the time available, and is personally relevant to and acceptable by the students.

(4) The environment or associated activities should support and provide opportunities for reflection, allow students to debrief from the game and contextualise their learning, and highlight the process of learning. (This makes the assumption that reflection is a requirement of all higher education learning activities.)

(5) The environment must provide an equitable experience for all users, taking into account and accommodating differing prior knowledge and experience of that world and similar environments. Ideally it should allow for personalisation and customisation and provide equal opportunities for all students to participate. Alternative pedagogic approaches should be available to students aligned to their personal learning preferences.

(6) The gaming world needs to provide ongoing support, from initial orientation to early tasks that provide quick initial success, with a gradual introduction of increasing complexity, supported with help, hints or clues to ensure that the environment does not become limiting. The gaming experience should aim to extend players to their extreme level of competence.

While these guidelines were developed from a constructivist standpoint, it is recognised that games can also be used effectively as instructional tools in adult learning contexts in further and higher education, adult and community learning, the corporate training sector 
and in military applications. For example, the most widely accessed 'serious game' is the Americas Army recruitment game with over 17 million downloads. In the game players are taken through a simulation of army basic training, career selection and into combat teams, and US army research suggests that there has been a marked decrease in the military training drop-out rates from those who have undertaken basic training in the Americas Army game prior to entry.

In this section some of the issues associated with the practicalities of using virtual gaming worlds to teach have been discussed. A range of options exist for creating different types of virtual gaming environments and these are explored in the following section.

\section{Selecting a virtual gaming environment}

A number of options of virtual gaming environments are available to the educator, from using off-the-shelf games software designed for entertainment, to creating a bespoke environment from scratch.

Some school-based practitioners use existing commercial games in a teaching context, for example using the Civilization game to teach history (Squire 2005) and in the Teaching with Games project undertaken by Futurelab and Electronic Arts (Sandford et al. 2006). This has the advantage of enabling students to use a high-end product, which has been explicitly designed to be engaging; however many commercial games are also expensive. Given the established business model where publishers commission development studios to develop content and pay ongoing royalties on unit (boxed) sales, developers insist, understandably, on royalty payments being applied against a minimum retail price, leaving little flexibility in respect of pricing for educational use. The technical architecture of commercial games makes the disaggregation of content almost impossible, an essential requirement if games are to be used in the time-constrained classroom environment. It can be difficult to exactly match the outcomes of the curriculum with those of the game so wrap-around briefing and debriefing activities are particularly important. Commercial gaming environments may also have complex interfaces, extensive functionality and a long learning period, which may detract from the intended learning outcomes. The long time taken to complete many games may also be far greater than a typical teaching timetable, however even given these limitations, innovative approaches to the use of games in the classroom have emerged, for example the innovative use of the Myst adventure game in English Literature (Rylands 2007).

The growing trend towards modifying existing games software for use in education (de Freitas 2007) may provide one way to address some of these issues. Many gaming environments now come with a creation engine that allows teachers, or students, to develop their own add-ons such as new storylines or game areas. This reduces development time and required expertise - but is still not a trivial process - and can help to ensure the links between learning and gaming outcomes.

A proliferation of available middleware and gaming engines, developed by the industry in order to negate spiralling development costs, are available to educators at increasingly affordable costs. For example many of Criterion's middleware tools are available to educators at no cost, and the Havoc gaming engine has been used in a number of educational projects such as the Virtual Multi User Learning Environment (VMULE) project, initially undertaken by the University of Liverpool and further developed by Futurelab (see www.futurelab.org.uk/projects/vmule). In parallel to this, open source tools and technologies such as OpenSim and Croquet are available to educators, but do require a degree of technical competency. 
As well as the option of using entertainment games, there are also a number of commercial gaming environments specifically designed for learning. However, these can be expensive and difficult to customise. Examples exist where the game exactly matches the subject area and learning outcomes and is suitable for students of a specific demographic (e.g. Whitton and Hynes 2006), but these are limited.

A growingly popular option is the use of existing virtual worlds such as Second Life (e.g. Childress and Braswell 2006) or MMORPGs for learning. These massive online worlds allow the interaction of thousands of players in real-time in virtual spaces; they can manipulate objects, solve quests, create and join groups, or work with others. Some worlds also allow users to create their own spaces and objects. Issues with using these worlds include the lack of privacy from other users who can wander into teaching spaces, the bad reputation that has built up over certain types of behaviour in these environments (for example violence in MMORPGs and the overtly commercial nature and sexual behaviour in MUVEs), and the high-specification machines and internet connections required to effectively run these applications. Hollins and Robbins (in press) have identified what they term the educational affordances of MUVEs, namely: identity, space, activity, tools and community.

Another option is the creation of a bespoke game, such as the action-adventure game developed to teach basic literacy skills to adults (Kambouri, Thomas, and Mellar 2006). This enables a designed match of learning outcomes with gaming outcomes for a specific user group. However, the problems associated with the design of bespoke education software involve the limited budgets compared to entertainment software, and how this affects the expectations of learners. Jenkins (2002) argues that most educational software is of poor quality, badly edited and unprofessional. It is unlikely, however, that the amounts of money spent on commercial software will be viable in education, and it is important that resources are focused on ensuring that educational games for adults are well designed in terms of playability and learning.

As well as viewing students as players of games (or merely consumers of content), they can learn by developing or creating games. Rieber et al. (1998) argues that learning by building games can be an at least, if not more, effective way to learn than traditional methods, while Gee (2003) argues that active, critical learning should lead to learners becoming designers, either by physically designing extensions to the game or by cognitively extending the game design and using that to inform their play.

A solution to the problem of finding a gaming environment that is fit-for-purpose, customisable and relatively inexpensive could be the alternate reality game (ARG). An alternate reality game is a type of interactive fiction that unfolds over a period of time, and requires puzzles to be undertaken collaboratively in order to progress the story. An ARG consists of three elements: a series of challenges, an underlying narrative, and a collaborative community, and while all three elements can be facilitated online, many challenges take place in the real world, and may be collaborative or individual. ARGs have been typically used for marketing and publicity (e.g. see Rose 2007) but also have potential in education for providing purposeful and motivating collaborative activities to contextualise learning.

Alternate reality games have a number of advantages over commercial games or developing fully online games from scratch. They are lo-fidelity, combining a range of web technologies so, while they do require some expertise and creativity to design, they are far cheaper and faster to create than developing high-end software, and can ensure that specific learning outcomes are met. As they involve the integration of web technologies such as blogs, wikis, and social networking software, they provide users with the experience of different technologies. Although ARGs do require ongoing monitoring and moderating of 
the community, this task is often undertaken by enthusiastic 'expert' players who can also get involved with building and extending the game.

Examples of how ARGs can be used in education are provided in the Alternate Reality Games for Orientation, Socialisation and Induction (ARGOSI) project (see www.playthinklearn.net/argosi.htm) and the Futurelab Virtual Savanagh project (see www.futurelab.org. uk/projects/savannah).

\section{Conclusions}

This paper has examined the use of collaborative virtual gaming worlds in the context of higher education, looking at the pedagogic advantages, practical considerations and issues of selecting an appropriate environment.

In using these types of environment it is important to ensure that there is a sound pedagogic rationale, which is clearly communicated, and they are not simply being adopted for a perceived motivational effect. Creating effective educational gaming worlds can be expensive, in terms of development time and expertise as well as financially, and it is essential to ensure that there are actual benefits to their use. Creating 'good' games is extremely challenging as an undertaking in itself; even the commercial sector struggles to achieve a $20 \%$ success, using unit sales as the metric.

The future for virtual gaming in higher education may be twofold: first, where collaborative activities in the constructivist philosophy may be based around the use of environments where a low (financial) cost of entry exists, such as alternate reality games or Second Life; and second, for skills development in photo-realistic simulation activities - such as currently undertaken in the military and medical sectors - where development budgets have historically been significantly higher. Whether higher education practitioners will consider adopting commercial off-the-shelf(COTS) products could be a subject of further research and analysis.

The novelty effect of using such environments should also be considered - both from the perspective of teacher and student - as this may influence long-term acceptability and effectiveness. It is also crucial that these environments do not lead to unintended exclusion of some users, for example those individuals who find it difficult to navigate within threedimensional spaces. Linking the use of these virtual worlds to appropriate and authentic assessment activities will also be one of the key challenges within the context of university education. However, there are extremely active teaching and research communities emerging around the use of gaming environments, the Second Life Educational (SLED) community being a case in point.

In all, while there are, as highlighted in this paper, examples of the effective use of immersive gaming environments in the context of adult learning in higher education, there is a clear need for more ongoing and robust studies into the potential of different types of virtual worlds, studies that recognise the significant issue of the context of use. This will help to ensure that as innovative and effective practices emerge, they can be evaluated in the context of the student learning experience and integrated into the growing body of knowledge on learning in virtual gaming worlds.

\section{References}

Beasley, N., and A. Crerar. 2005. Motivations for adults playing games. In Proceedings of ISAGA 2005, June 27-July 1, in Atlanta.

Bloom, B.S. 1956. Taxonomy of educational objectives, Handbook I: The cognitive domain. New York: David McKay Co. Inc. 
de Freitas, S. 2007. Learning in immersive worlds: A review of game-based learning. Bristol: JISC.

Childress, M.D., and R. Braswell. 2006. Using massively multiplayer online role-playing games for online learning. Distance Education 27, no. 2: 187-96.

Ducheneaut, N., and R.J. Moore. 2005. More than just 'XP': Learning social skills in massively multiplayer online games. Interactive Technology \& Smart Education 2: 89-100.

Egenfeldt-Nielsen, S. 2005. Beyond edutainment: Exploring the educational potential of computer games. PhD diss., IT-University Copenhagen, Denmark.

Gee, J.P. 2003. What video games have to teach us about learning and literacy. New York: Palgrave MacMillan.

Grabinger, S., J. Dunlap, and J. Duffield. 1997. Rich environments for active learning. ALT-J 5, no. 2: $5-17$.

Hollins, P., and S. Robbins. In press. Educational affordances of Multi-User Virtual Environments. In Living virtually: Researching new worlds, ed. D. Heider. New York: Peter Lang Publishing.

Honebein, P.C. 1996. Seven goals for the design of constructivist learning environments. In Constructivist learning environments: Case studies in instructional design, ed. B.G. Wilson, 11-23. Englewood Cliffs, NJ: Educational Technology Publications.

Hughes, M. 2006. Welcome to SimPLE. http://technologies.law.strath.ac.uk/simple2/index.php? option $=$ com_content\&task=view\&id=17\&Itemid $=38$.

Jenkins, H. 2002. Game theory. Technology Review March. http://www.technologyreview.com/ energy/12784/? $\mathrm{a}=\mathrm{f}$

Kambouri, M., S. Thomas, and H. Mellar. 2006. Playing the literacy game: A case study in adult education. Learning, Media and Technology 31, no. 4: 395-410.

Knowles, M. 1998. The adult learner. 5th ed. Houston, TX: Butterworth-Heinemann.

Kolb, D.A. 1984. Experiential learning: Experience as the source of learning and development. New Jersey: Prentice Hall.

Land, S.M., and M.J. Hannafin. 2000. Student-centered learning environments. In Theoretical foundations of learning environments, ed. D.H. Jonassen and S.M. Land, 1-23. Mahwah, NJ: Lawrence Erlbaum Associates.

Lave, J., and E. Wenger. 1991. Situated learning. Legitimate peripheral participation. Cambridge: University of Cambridge.

McConnell, D. 2000. Implementing computer supported cooperative learning. 2nd ed. London: Kogan Page.

Palloff, R.M., and K. Pratt. 2003. The virtual student: A profile and guide to working with online learners. San Francisco: Jossey-Bass.

Prensky, M. 2001. Digital game-based learning. New York: McGraw Hill.

Rieber, L. 1996. Seriously considering play: Designing interactive learning environments based on the blending of microworlds, simulations and games. Education and Training Resource \& Development 44: 42-58.

Rieber, L.P., L. Smith, and D. Noah. 1998. The value of serious play. Educational Technology 38, no. 6: 29-37.

Rose, F. 2007. Secret websites, coded messages: The new world of immersive games. Wired. http:// www.wired.com/entertainment/music/magazine/16-01/ff_args.

Rylands, T. 2007. ITC to inspire with Myst. http://www.timrylands.com/index.html.

Sandford, R., M. Ulicsak, K. Facer, and T. Rudd. 2006. Teaching with games: Using commercial off-the-shelf computer games in formal education. Bristol: Futurelab. www.futurelab.org.uk/ download/pdfs/research/TWG_report.pdf.

Squire, K.D. 2005. Changing the game: What happens when videogames enter the classroom? Innovate 1, no. 6 . http://innovateonline.info/index.php?view $=$ article $\& \mathrm{id}=82$

Steinkuehler, C.A. 2004. Learning in massively multiplayer online games. In Proceedings of the 6th International Conference on Learning Sciences, 22-26 June, in Santa Monica, California.

van Ments, M. 1995. The development of simulation and gaming in Britain: A SAGSET view. Simulation \& Gaming 26, no. 2: 224-35.

Whitton, N. 2007. An investigation into the potential of collaborative computer game-based learning in higher education. $\mathrm{PhD}$ diss. www.playthinklearn.net.

Whitton, N., and N. Hynes. 2006. Evaluating the effectiveness of an online simulation to teach business skills. E-Journal of Instructional Science and Technology 9, no. 1. http:// www.usq.edu.au/electpub/e-jist/docs/vol9_no1/papers/current_practice/Whitton_Hynes.htm 